\title{
TAPERED STEEL ENERGY DISSIPATORS FOR EARTHQUAKE RESISTANT STRUCTURES
}

\author{
R. G. Tyler*
}

\begin{abstract}
The paper describes the testing and design of tapered-steel cantilevers used as energy dissipating devices, manufactured from either round bar or plate, which can be used in isolation systems to protect buildings or bridge decks against earthquake attack. The steel cantilever energy absorber is a simple device which can be manufactured from steel supplies normally available in an engineering stores using standard engineering practice.
\end{abstract}

\section{INTRODUCTION}

Methods for the base isolation of structures have been developed by the Engineering seismology section of the physics and Engineering Laboratory to improve resistance against earthquake attack. Systems suitable for buildings using hysteretic dampers and laminated rubber bearings (1-3) have already been described. The application to bridge decks has also been discussed $(4)$.

In this paper, the results of tests carried out on tapered steel energy dissipators are given, together with the design methods which have evolved. By employing a taper, the metal along its length is utilised for energy absorption to the fullest extent, which makes for a compact device which has found application in a stepping chimney at Christchurch and in a bridge in Dunedin. The round type was developed because of its suitability for providing damping in any direction in a horizontal plane in a base isolated building and the plate type for its cheapness in providing damping in a single direction.

\section{TYPE OF STEEL}

Mild steels have been used exclusively for this type of energy dissipators. For the plate type they have been black to specification BS $4360 / 43 \mathrm{~A}$ and, for the round type, either black to the same specification, or bright to Australian Standards CS 10308 or CS 10208, which have a similar chemical composition. They have been stress relieved after welding for 5 hours at $620^{\circ} \mathrm{C}$, which for bright bars restores the material to a normal yield point, and is also believed to be beneficial from the point of view of age embrittlement(5). The possibility of age embrittlement is not of great concern, however, as it would be possible to replace the absorbers following a major earthquake, if tests, which are planned, demonstrate that this is desirable.

Low-carbon steels were tried in the belief that the long stress-strain curve obtained in static tension would give enhanced fatigue life. However, this did

* Physics and Engineering Laboratory, Department of Scientific and Industrial Research, Gracefield, Wellington. not occur and, for the same strain level, the damping forces were lower as compared with steels to BS 4360/43A. Pure aluminium and spheroidal graphite iron were also tried with results less satisfactory than with mild steel.

Hot-dip galvanising has been suggested as a galvanising protection but, because of the lack of knowledge of the effects of galvanising over long periods, when the steel may be subjected to high strains, its use is not recommended.

\section{TEST DETAILS}

\subsection{General}

Testing was carried out on full-scale or nearly full-scale components, mainly using a bulldozer test machine adapted for linear dynamic testing by means of an eccentric connected to its rear drive, and at frequencies of loading in the range 0.2 to $0.9 \mathrm{~Hz}$, in the same way as was done for tests on other devices $(6-8)$. Later a rig employing a hydraulic jack operating at about 1 cycle every 4 minutes was used. The output from a load cell in the drive of both testing units, and from an LVDT recording the movement of the load point of the cantilever relative to its base, were fed into an XY plotter to give hysteresis loops. The strain range was measured statically by means of a $50 \mathrm{~mm}$ Demec gauge, using points stuck on the steel surface with an epoxy resin adhesive over the length of the taper, and taking readings at the extremes of the travel. The strain range measured in this way is the sum of the elastic and plastic strain changes in a half cycle.

\subsection{Stress Level}

For a section of a cantilever carrying a force $Q_{d}$ (Fig. 1) yielding under a constant plastic stress $f_{p}$, as previously outlined in the companion paper(7)

$\mathrm{Q}_{\mathrm{d}} \mathrm{x}=\mathrm{Kf}_{\mathrm{p}}$

where

$\mathrm{x}=$ distance from load point to section, and

$\mathrm{K}=$ plastic modulus, which is a function of $\mathrm{x}$ 
$=d^{3} / 6$ for a circular section of diameter $d$

$=B t^{2} / 4$ for a rectangular section of breadth $B$ and thickness $t$.

In practice under cyclic loading, the size of the hysterestis loop increases as the strain range increases. See Fig. 8 of the companion paper $(7)$. Hence $Q_{d}$, which is taken as the force ordinate when the damper passes through zero deflection, and $f_{p}$, increase with strain level; also it is unlikely that $f_{p}$ has a constant value through the section because of a greater work hardening effect at the surface. It is, however, convenient to calculate a value of $f_{p}$ using equation (I) and relate this to strain level. This enables the size of the device to be determined from the required damping force, taken as approximately 5 per cent of the building weight(1).

\section{ROUND TYPE}

\subsection{General}

The round type provides damping in two directions at right angles and was originally promoted with a view to use in the base isolation of buildings, where motion is controlled in the horizontal plane.

For all sections along a taper to become plastic simultaneously the relationship between diameter $d$ and distance $x$ (Fig. $l(a)$ and equation 1 ) is:

$\mathrm{d}^{3}=6 \mathrm{Q}_{\mathrm{d}} \mathrm{x} / \mathrm{f}_{\mathrm{p}}$

when $\mathrm{x}=\mathrm{L}, \mathrm{d}=\mathrm{D}$ at the cantilever root, this gives $6 Q / f_{p}=D^{3} / L$

$$
\text { i.e. } \quad d=D^{3} \sqrt{\frac{x}{L}}
$$

The same equation is obtained if all sections are considered to commence yielding simulataneously at the extreme fibres and the design is based on an elastic analysis.

For tapers up to about two-thirds of the length of the cantilever, measured from the root of the cantilever, the optimum shape can be approximated by machining the taper straight, from one end to the other, with the diameter at the top of the taper (section Z, Fig. 1) determined from equation (2). This results in a slight undercut at the centre of the length, which promotes a failure within the length of the taper rather than at the basal fixity, where stress raisers normally promote a failure.

The principle adopted in fabrication of test specimens was to keep welding away from the highly strained part of the cantilever. For the fixity, the proportions indicated in Fig. 2 were adequate, the cantilever of root diameter $D$ being a push fit in the cylinder of overall diameter $2 \mathrm{D}$ and height D. The base plate is a square of side 4D and thickness $\mathrm{D} / 2$. Because of distortion the base plate was machined flat after welding and stress relieving.

\subsection{Testing for Development of Design Method}

Two types of round cantilever were tested ${ }^{(8)}$, both having a root diameter of $76 \mathrm{~mm}$. The first was a single cantilever, having a taper over about one-third of its length (Fig. 2) and the second a double cantilever, each cantilever having a taper over about two-thirds of its length (Fig. 3).

The first type failed after 132 cycles within the length of the taper (Plate 1); the strain range was not measured, but from the fatigue relationship (Fig. 9 of the companion paper (7), it may be estimated as $\pm 3 \%$. The hysteresis loop obtained is shown in Fig. 4. The approximate values for the slopes of the equivalent bilinear loop, $\mathrm{K}_{\mathrm{d}} / \mathrm{Q}_{\mathrm{d}}=85 \mathrm{~m}^{-1}$ and $\mathrm{kd} / \mathrm{Qd}_{\mathrm{d}}=5 \mathrm{~m}^{-1}$, have already been reported ${ }^{(9)}$.

The second type (Plates 2 and 3) was tested intermittently over a period of two months and finally failed, again within the length of the taper, after 1160 cycles. The strain range was measured over the length of the taper and was found to be nearly constant at $\pm 1.0 \%$. The loop obtained, scaled for one-half of the cantilever, is shown in Fig. 5. Per cantilever the stroke was about half that obtained for the first cantilever (Fig. 4), and the induced strain less than half because of the extra flexibility of the taper. The corresponding energy represented by the area of the loop is about one quarter, showing the effect of halving the strain on energy absorption. The reduction arises because proportionately there is greater energy stored in elastic strain.

The fatigue life was collated with others obtained on small scale specimens at the Laboratory $(8)$, and by Horwood and White in the United Kingdom(10), to give the fatigue relationship shown in Fig.9 of the companion paper(7), this relationship being applicable to smooth circular bars in bending. The effect of roughness or other stress raisers, such as entry. into a fixity, is generally to reduce the fatigue life.

Another cantilever was machined to take the place of the failed one and, after some further testing, both cantilevers were stored to check for age embrittlement over a period of years.

\subsection{Test Results}

Test results are summarised in Table 1 . The plastic stress $f_{p}$ was calculated using equation (I) e.g. for the first cantilever tested:

$$
f_{p}=6 Q_{d} L / D^{3}
$$

where $Q=54 \mathrm{kN}$ (Fig. 5), $\mathrm{L}=0.47 \mathrm{~m}$ and

$$
\mathrm{D}=0.076 \mathrm{~m} \text {, }
$$

$$
\text { giving } \quad \mathrm{f}_{\mathrm{p}}=344 \mathrm{MN} / \mathrm{m}^{2}
$$

For the double cantilever damper, which was tested at the lower strain range of $2 \%, f_{p}$ was $191 \mathrm{MN} / \mathrm{m}^{2}$. Samples of the steel tested statically in a tensile test machine gave a yield point of $290 \mathrm{MN} / \mathrm{m}^{2}$, thus indication that at the $2 \%$ strain range a portion of the section was still elastic. 
cycle (Qmax $\left.-Q_{d}\right) / Q_{d}$ is seen to be greater for the double cantilever (53\%) than the single (37\%). This is because of the lower strain level; the effect may be observed in the family of loops (Fig. 8 of the companion paper (7).

\section{THE PLATE TYPE}

\subsection{General}

The plate type was first suggested as a unidirectional device for use in the isolation of bridge decks but has also found application in a chimney designed to step under earthquake attack. In this type the breadth $b$ at any distance $x$ from the load point is linear with $x$ for yield to develop along the whole length simultaneously. Again, the maximum length of taper adopted was about $2 / 3 \mathrm{~L}$.

\subsection{Testing for Development of Design Method}

Testing was aimed at proving an adequate base detail in the inverted ' $T$ ' type for the bridge application, where the absorber would be bolted down to the top of a pier or abutment and would be loaded by movement of the deck above.

A simple butt joint would not be adequate as even if the base plate did not delaminate, the weld would not withstand the high strain for very many cycles of loading.

\subsubsection{The Split Type}

In this design the vertical plate was split at its wide end, opened out and welded (Plate 4). It failed after 75 cycles at a strain range of $3.5 \%$ (Table 1 ), at the bend at the bottom of the taper. This life was reasonable, if reduced, compared with that estimated using the fatigue relationship (Fig. 9, Ref. 7), but was not adopted because of the expense of manufacture at full scale.

\subsubsection{The Seam Welded Type}

This absorber was fabricated by seam welding two I shaped plates back to back down the sloping edges (Plate 4 ), to the same taper dimensions and thickness as the split type. It failed at 70 cycles at a strain range of $2.4 \%$ (Table 1 ), again at the base of the taper, which was a reduced life compared with the split type. Accordingly the design was not adopted.

\subsubsection{The Buttressed Type}

In this type the conventional butt joint was reinforced with plates and $45^{\circ}$ fillets on either side, the vertical plate having the same taper dimensions and thickness as for the preceding types (Fig. 6 and Plate 5). In fabricating the base, the principle was again adopted that welding was kept well away from the highly strained section of the plate.

The device tested had a life of 127 cycles at a maximum strain range of $4.2 \%$, recorded about $2 / 3$ of the way up the taper; this life was better than obtained previously but again less than that indicated by the fatigue relationship. This was probably because the primary failure was in a groove caused by roughness in the flame cutting at the top of the taper, which shows the desirability of a smooth finish. on stripping out the absorber from the test machine it was found that the welds at the base of the plate had also failed, although this apparently did not affect the performance.

\subsection{Test Results}

Results obtained during the initial testing work are given in Table 1 . The plastic stress $f_{p}$ was calculated using equation (1), e.g. for the buttress type

$$
\begin{aligned}
& f_{p}=4 Q_{d} L / B t^{2} \quad \text { where } Q_{d}=78 \mathrm{kN} \\
& \text { giving } f_{p}=308 \mathrm{MN} / \mathrm{m}^{2} \quad B=213 \mathrm{~mm} \\
& \mathrm{~L}=305 \mathrm{~mm}
\end{aligned}
$$

In Fig. 8 of the companion paper (7), values of $\mathrm{f}_{\mathrm{p}}$ have been plotted against strain range. In addition the number of cycles to failure have been superimposed on the curve for fatigue life previously derived for smooth round bars (Fig. 9 of the companion paper(7)). This shows that the fatigue life for the buttress type was a little less than that derived for smooth round bars, but about equivalent to the mean obtained for the bent bar tests ( 7$)$.

The values for $\left(Q \max -Q_{d}\right) Q_{d}$ show that, as for the round type, the rise to the peak load Qmax decreases as the strain range increases, the hysteresis loops for the plate absorber have not been reproduced but were generally similar in shape to those shown in Figs. 4 and 5 for the round ones.

\section{DESIGN OF TAPER DAMPERS}

\subsection{General}

The cantilever must be sufficiently strong to develop the required damping force, while at the same time the load point must move through range of movement, $\pm y$, appropriate to the design earthquake, developing the strain $\pm \varepsilon$ in surface layers along the length of the taper. In Appendix 1 it is shown that, for calculation purposes, the taper may be assumed to extend right up to the load point.

From the fatigue curve Fig. 9 of the companion paper(7), a range of strain of $\pm 3 \%$ will usually give a life of 80 cycles unidirectionally, even allowing for some imperfection in detail design, while conservatively, this level of strain is produced by a value of the plastic stress $f_{p}$ equal to $350 \mathrm{MPa}$ (Fig. 8 of the companion paper(7),

\subsection{Round Damper}

To satisfy the strength and deflection conditions it can be shown that (see Appendix 1 and Fig. 1) :

$L^{2}=D Y / I .2$

$\mathrm{Q}_{\mathrm{d}}{ }^{2}=3.33 \times 10^{-2} \varepsilon \cdot \frac{\mathrm{D}^{5} \mathrm{f}_{\mathrm{p}}{ }^{2}}{\mathrm{y}}$ 
Substituting $\mathrm{f}_{\mathrm{p}}=350 \mathrm{MPa}$ and $\varepsilon=0.03 \mathrm{in}$ (3) and (4), for a life of 80-100 cycles, gives:

$L=5.270 \sqrt{D Y}$
$Q_{d}=11.067 \sqrt{D^{5} / y}$

Values of $L$ and $Q_{d}$ appropriate to a range of displacements $y$, for a range of bar diameters D, are plotted in Fig. 7 . Normally, for the building isolation application y would be taken as $\pm 75 \mathrm{~mm}$, but for bridge decks or stepping structures other values may be appropriate.

As an example of the use of Fig. 7, if a damping force of $100 \mathrm{kN}$ is required for a deflection $y= \pm 75 \mathrm{~mm}$ then the required root diameter is about $92 \mathrm{~mm}$ (point A) and the damper length is about $430 \mathrm{~mm}$ (point B). For calculations, it is suggested that the values of $\mathrm{K}_{\mathrm{d}} / \mathrm{Q}_{\mathrm{d}}$ and $\mathrm{k}_{\mathrm{d}} / \mathrm{Q}_{\mathrm{d}}$ be taken as $85 \mathrm{~m}^{-1}$ and $5 \mathrm{~m}^{-1}$ respectively as previously derived (Para. 4.2).

Under disaster conditions, with a possible range of movement $\pm 150 \mathrm{~mm}$, say the strain would rise to $\pm 6 \%$, i.e. a range of $12 \%$, and the cantilever would possibly complete 10-20 unidirectional cycles before failing (Fig. 9 of the companion paper (7)). For this condition $f_{p}$ would rise from $350^{\circ}$ to about $500 \mathrm{MPa}$ (extrapolating from Fig. 8 of the companion paper(7)) and $Q$ correspondingly to $500 \times 100 / 350=143 \mathrm{kN}$. Also a reduced value could be taken for the second slope $k_{d} / Q_{d}$ as the fractional rise $\left(Q_{\max }-Q_{d}\right) / Q_{d}$ would be less.

\subsection{Plate Damper}

The corresponding equations for the plate damper (see Appendix 1) are:

$L^{2}=t_{y} / E$

$Q_{d}=f_{p} B t^{2} / 4 L$

In determining dimensions from these equations a value for the ratio B:L must be chosen. For the absorbers so far designed by the Laboratory $\mathrm{B}=2 \mathrm{~L} / 3$ approximately. Substituting this condition in (8) gives

$Q_{d}=f_{p} t^{2} / 6$

Substituting $\mathrm{f}_{\mathrm{p}}=350 \mathrm{MN} / \mathrm{m}^{2}$ and $\mathrm{E}$ $=0.03$ in (7) and ( 9 ) gives :-

$L=5.774 \sqrt{t y}$

$Q_{d}=58.333 t^{2}$

Values of $L$ and $Q_{d}$ are plotted in Fig. 8 for a range of plate thicknesses and displacements. It is to be noted that, for plate dampers having $B$ equal to some fraction of $L$ the damping force $Q_{d}$ depends only on the plate thickness, since as L increases, the plastic modulus, which depends on $B$, increases proportionately.

As an example of the use of Fig. 8, if a damping force of $150 \mathrm{kN}$ is required for a deflection $\mathrm{y}= \pm 75 \mathrm{~mm}$ then the required plate thickness is $51 \mathrm{~mm}$ (point $\mathrm{W}$ ) and the damper length is about $0.35 \mathrm{~m}$ (Point $\mathrm{V}$ ). For calculations, the values for the slopes $\mathrm{K}_{\mathrm{d}} / \mathrm{Q}_{\mathrm{d}}$ and $\mathrm{k}_{\mathrm{d}} / \mathrm{Q}_{\mathrm{d}}$ may be taken as for the round type (Para. 6.2).

\section{APPLICATIONS}

\subsection{Energy Dissipators for Stepping Chimney at Christchurch}

Two steel plate absorbers were installed at the base of a chimney at Christchurch in 1977 (Plate 6 and Fig. 9), in consultation with the designers, to control stepping in two directions at right angles under earthquake loading in the same way as for the Rangitikei Railway Bridge (9).

The design of the fixing details was based on earlier small-scale tests and was not tested on the full-scale. The plates were cut commercially using a profile cutter which facilitated the introduction of the flaring of the taper into the fixity.

On the assumption that the device has approximately the same overall stiffness as the buttress type of damper, the force per damper for a $60 \mathrm{~mm}$ plate is about $100 \mathrm{kN}$. for $f_{p}=350 \mathrm{MN} / \mathrm{m}^{2}(\mathrm{Fig} .8)$, while the range of deflection, corresponding to $\mathrm{L}=300 \mathrm{~mm}$, is about $\pm 70 \mathrm{~mm}$; i.e. a $140 \mathrm{~mm}$ uplift, since the damper will take on a new median position after the first cycle.

\subsection{Plate Dissipators for King Edward Street Overpass, Dunedin}

The design of this bridge called for $250 \mathrm{kN}$ plate dissipators at both piers and abutments and has been described elsewhere (10). The dampers were designed using raw data prior to the completion of Fig. 8. Using Fig. 8, a force of $250 \mathrm{kN}$ requires a plate thickness of $65 \mathrm{~mm}$ and a cantilever length of about $0.4 \mathrm{~m}$ for a deflection of $\pm 75 \mathrm{~mm}$. A plate thickness of $65 \mathrm{~mm}$ was, in fact, provided for the production units with a cantilever length of $0.42 \mathrm{~m}$ (Fig. 10). This slightly greater length had the effect of reducing the maximum strain level at the design deflection from $\pm 3 \%$ down to $\pm 2.8 \%$, see Table 2 , and the force to about $230 \mathrm{kN}$.

The dissipator tested was the first production unit, a further 12 units being fabricated for the bridge structure. Testing was carried out in a testing frame, Plate 7, using a double acting ram giving about 1 cycle every 4 minutes. Whereas testing had hitherto been carried out a constant stroke and the number of cycles to failure noted, for these tests it was decided to vary the stroke, as this facility was available using the jack. This allows the variation in amplitude of a single very large earthquake or group of earthquakes to be studied. The proposal was to perform:

$$
\begin{aligned}
& 1 \text { cycle at } \pm 150 \mathrm{~mm} \text { deflection } \\
& \begin{array}{rllll}
4 & \text { " } & \pm 100 \mathrm{~mm} & " & \\
30 & " & \pm 75 \mathrm{~mm} & " & \text { (the design } \\
00 & \text { " } & \pm 50 \mathrm{~mm} & \text { " } & \text { level) }
\end{array}
\end{aligned}
$$

After 2 cycles were carried out at strokes (peak to peak) of 23, 55 and $93 \mathrm{~mm}$ respectively, to enable a family of loops to be 
built up (Fig. Il), a further 30 cycles were carried out at about $150 \mathrm{~mm}$ stroke, followed by 85 at $100 \mathrm{~mm}$ stroke (Table 3) whereupon the dissipator failed about halfway along the taper (Plate 9).

This performance was considered to be satisfactory, but the question of a standard sequence of loading in future testing is raised, and also the effect of cumulative damage, as the planned programme was not completed. It is conceivable, for instance, that the dissipator would have survived 100 cycles at $\pm 50 \mathrm{~mm}$ followed by 30 at $\pm 75 \mathrm{~mm}$, whereas it did not survive the loading in the reverse sequence.

The strains recorded by a Demec gauge using 5 sequential stations down the length of the taper on both sides of the plate are given in Table 2. Because of adjustments to the testing rig, 4 cycles were inadvertently performed at $162 \mathrm{~mm}$ stroke, prior to adjusting back to $150 \mathrm{~mm}$, and a maximum strain range of $6 \%$ was reached during these cycles. Pro rata at the design level of $\pm 75 \mathrm{~mm}$, the maximum strain range would be about $5.6 \%$.

It is seen from Table 2 that the strains were greatest towards the top of the taper. This suggests that the shear forces, which were neglected in the design, add to the plastic flow at the minimum cross section where their effect is greatest. In future designs of the plate type, the width of the taper at its top could be increased by about $10 \%$ with benefit, and the flare at the base of the taper reduced somewhat, as strains there were not critical.

The loops, Fig. 11, show asymmetry because of the effect of the loading lug on the bending moment in the extreme positions (Plate 8 ), the moment being increased on the push stroke and decreased on the pull stroke. This led to a drift in the plastic strains (Table 2) and a permanent bend in the device. Thus strains recorded on the two sides of the device (Table 2) are different. In the bridge, the movement takes place in a symmetrical guide and the strains on both sides should be the same.

On stripping down the dissipator from the test frame it was found that the welds at the root of the ' $T$ ' had failed and it was possible to remove the leg of the cantilever from the buttresses (Plate 9). Inspection of the records showed that the failure, evidenced by steps in the hysteresis loops on reversal of the load, occurred after about 30 cycles at $\pm 50 \mathrm{~mm}$ deflection following completion of the 30 cycles at about $\pm 75 \mathrm{~mm}$ deflection. Performance of the dissipator was little affected however up to the time of the failure in the main taper. The early weld failure was caused by a $2 \mathrm{~mm}$ gap showing on each side between the main cantilever and the buttresses on delivery, caused by shrinkage following welding in the first production unit. For the units supplied to the bridge site the welding technique was changed and additional machining carried out which completely closed these joints. Failure of the welds in these units during an earthquake is therefore less likely. $\mathrm{k}_{\mathrm{d}} / \mathrm{Qd}$ obtained from the loops for the $150 \mathrm{~mm}$ deflection range were approximately $72 \mathrm{~m}^{-1}$ and $3.8 \mathrm{~m}^{-1}$, which is less than the values recommended in paragraph 4.2 , i.e. $85 \mathrm{~m}^{-1}$ and $5 \mathrm{~m}^{-1}$. It is suggested, however, that until further test results become available, the latter values are adopted in design.

\section{CONCLUSION}

Tapered steel cantilever energy absorbers are simple devices which can be manufactured from steel supplies normally found in an engineering stores using standard engineering practice. They have a predictable performance and the advantage of a greater energy absorbing capacity as strains increase and failure is approached.

It is suggested that for design purposes the slopes of the bilinear loop at a design strain range of $6 \%$ be taken as $\mathrm{k}_{\mathrm{d}} / \mathrm{Q}_{\mathrm{d}}=85 \mathrm{~m}^{-1}$ and $\mathrm{k}_{\mathrm{d}} / \mathrm{Q}_{\mathrm{d}}=5 \mathrm{~m}^{-1}$.

\section{REFERENCES}

1. Skinner, R. I., Beck, J. I. and Bycroft, G. N., "A Practical System for Isolating Structures from Earthquake Attack". Earthquake Engineering and Structural Dynamics 3, p.297-309, 1975.

2. Skinner, R. I., Heine, A. J. and Tyler, R. G.," "Hysteretic Dampers to Provide Structures with Increased Earthquake Resistance". Proceedings Sixth World Conference on Earthquake Engineering, New Delhi, January 1977.

3. Robinson, W. H. and Greenbank, L. R., "An Extrusion Energy Absorber Suitable for the Protection of Structures During an Earthquake". Earthquake Engineering and Structural Dynamics 4, p.251-259, 1976.

4. Blakeley, R. W. G., "Prestressed Concrete Bridges Incorporating Mechanical Energy Dissipating Devices for Earthquake Resistance". Technical contribution to 8 th Congress, Federation Internationale de la Precontrainte, London, May 1978.

5. Erasmus, L. A. and Pussegoda, L. N., "Strain Age Embrittlement of Reinforcing Steels". N.Z. Engineering 32, No. 8, August 1977.

6. Tyler, R. G., "Dynamic Tests on Laminated Rubber Bearings". Bull. N.Z. Nat. Soc. Earthq. Eng., Vol. 10, No. 3, September, 1977 .

7. Tyler, R. G., "A Tenacious Base Isolation System Using Round Steel Bars". Bull. N.Z. Nat. Soc. Earthq. Eng., Vol. 11, No. 4, December, 1978.

8. Tyler, R. G. and Skinner, R. I. "Testing of Dampers for the Base Isolation of a Proposed 4-Storey Building Against Earthquake Attack" . Proc. Sixth Aust. Conf. Mech. Str. and Mats. Univ. of Canterbury N.Z., August 1977.

9. Beck, J. L. and Skinner, R. I., "The Seismic Response of a Reinforced Concrete Bridge Pier Designed to step". Earthquake Engineering and Structural Dynamics, 2 1974, pp.343-358.

10. Park, R. G., Blakeley, R. W. G., "Seismic Design of Bridges", Road Research Unit, National Roads Board, Bridge Seminar, 1978. 


\section{APPENDIX I}

\section{Deflection of Taper Dampers}

\section{(1) Round Damper}

Strength condition: using equation

$L=K f_{p} / Q$ where $K=D^{3} / 6$

i.e. $L=D^{3} f_{p} / 6 Q$

Deflection condition: the deflection $y^{\prime}$ at the load point caused by flexure over the length of the taper is given by:

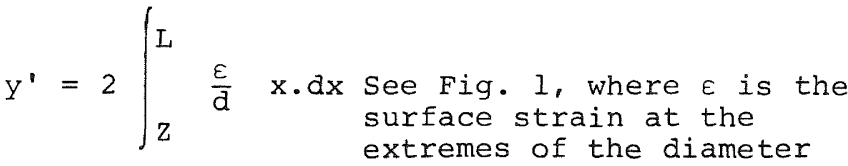
in the plane of bending

substituting $d=D \cdot \sqrt[3]{\frac{x}{L}}$ and solving gives

$y^{\prime}=1.2 \frac{\varepsilon}{D}\left(L^{2}-L^{1 / 3} z^{5 / 3}\right)$

For the usual condition $\mathrm{z}=\mathrm{L} / 3$

$Y^{\prime}=1.008 \varepsilon L^{2} / D$

To this must be added the deflection $y^{\prime \prime}$ of the parallel shank above the taper. If the strain over this length is assumed to diminish linearly from at the top of the taper to $O$ at the load point, with a strain $\varepsilon^{\prime}$ at section $x_{2}$ distant $x_{2}$ from the load point (Fig. 1).

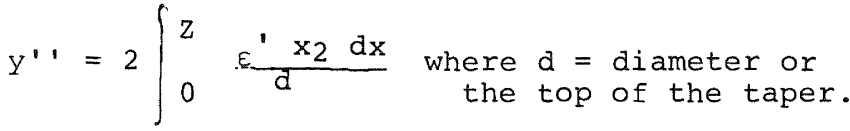

Putting $\varepsilon^{\prime}=x_{2} \quad \varepsilon / z$ and $d=D, \sqrt[3]{Z / L}$ gives:

$y^{\prime \prime}=2 \varepsilon \cdot z^{5 / 3} \cdot L^{1 / 3} / 3 D$

For the usual case of $\mathrm{z}=\mathrm{L} / 3$

$y^{\prime \prime}=0.1068 L^{2} / D$

Thus the total deflection, $y=y^{\prime}+y^{\prime \prime}$ ', at the load point is given by:

$y=1.115 \in L^{2} / D$

But the taper is usually machined straight from one end to the other thus increasing the deflection. Also there is some movement into the fixity; hence take:

$y=1.2 \varepsilon L^{2} / D$

which is the value of deflection for the ideal taper over the full length $L$ of the cantilever (see equation $i$ ).

\section{(2) Plate Damper}

Strength condition: using equation

$Q_{\mathrm{d}} \mathrm{L}=\mathrm{f}_{\mathrm{p}} \mathrm{K}$ $\mathrm{K}=B t^{2} / 4$

$Q_{d}=f_{p} B t^{2} / 4 L$
Deflection condition: the deflection at the load point $y^{\prime}$ caused by flexure over the length $d x$ (Fig. 1) is given by:

$d y=\frac{2 \varepsilon x_{I}}{t} d x$

For the whole taper

$y^{\prime}=\frac{2 \varepsilon}{t} \int_{z}^{L} x_{1} d x$

i.e. $Y^{\prime}=\frac{\varepsilon}{t}\left(L^{2}-Z^{2}\right)$

Usually $\mathrm{z}=\mathrm{L} / 3$ giving $\mathrm{y}^{\prime}=0.0889 \mathrm{~L}^{2} / \mathrm{t}$

For the portion above the taper, if the surface strain is assumed to diminish

linearly from $\varepsilon$ to $O$ at the load point,

then the contribution to the tip deflection $y^{\prime \prime}$ ', may be estimated; viz at a typical section the surface strain $\varepsilon^{\prime}$ is given by $\varepsilon \mathrm{x}_{2} / \mathrm{Z}$, thus:

$y^{\prime \prime}=\frac{2}{t} \int_{0}^{z} \varepsilon^{\prime} x_{2} d x=\frac{2 \varepsilon}{t z} \int_{0}^{z} x^{2}, d x=2 \varepsilon z^{2} / 3 t$

But $z=L / 3 \quad y^{\prime \prime}=0.074 \varepsilon L^{2} / t$

Thus the total deflection, $y=y^{\prime}+y^{\prime} '$, at the load point is given by:

$y=0.963 \varepsilon \mathrm{L}^{2} / \mathrm{t}$

There is also flexibility into the fixity, as observed during testing, and flexibility at the flaring above the fixity.

$$
\text { Hence take } y=\varepsilon L^{2} / t
$$

which is the value of deflection for a cantilever having a taper over the full length $L$. (See equation $i x$ ) 
TABLE 1

RESULTS OF TESTS ON TAPER CANTILEVERS

\begin{tabular}{|c|c|c|c|c|c|c|c|c|c|c|}
\hline Cantilever Type & $\begin{array}{l}\text { Cross } \\
\text { Section } \\
\text { at Root } \\
(\mathrm{mm})\end{array}$ & $\begin{array}{c}\text { Length of } \\
\text { Cantilever } \\
\quad(\mathrm{mm})\end{array}$ & $\begin{array}{c}\text { Stroke } \\
(\mathrm{mm})\end{array}$ & $\underset{(\mathrm{kN})}{\mathrm{Qd}}$ & $\begin{array}{r}f_{p} \\
M P a\end{array}$ & $\begin{array}{l}\text { Cycles } \\
\text { to } \\
\text { Failure }\end{array}$ & $\begin{array}{l}Q \max \\
(\mathrm{kN})\end{array}$ & $\frac{Q_{\max }-Q_{\mathrm{d}}}{Q_{\mathrm{d}}}\left(\frac{\circ)}{(\%)}\right.$ & $\begin{array}{l}{ }^{*} k_{d} / Q_{d} \\
\left(m^{-1}\right)\end{array}$ & $\begin{array}{l}\text { Measured } \\
\text { Strain } \\
\text { Range } \\
\text { (Peak to } \\
\text { Peak) }\end{array}$ \\
\hline Single round & $\begin{array}{l}76.2 \mathrm{~mm} \\
\text { dia. }\end{array}$ & 470 & 139 & 54 & 344 & 132 & 74 & 37 & 5.3 & $6.0+$ \\
\hline Double cantilever round & " & $\begin{array}{l}470 \\
\text { each }\end{array}$ & $\begin{array}{l}74 \\
\text { each }\end{array}$ & 30 & 191 & 1160 & 46 & 53 & 14.3 & 2.0 \\
\hline Fork ended plate & $\begin{array}{l}38.1 \mathrm{~mm} \\
\times \quad 213\end{array}$ & 305 & 83 & 75 & 296 & 75 & 110 & 46 & 11.1 & 3.5 \\
\hline Seam welded plate & " & " & 70 & 46 & 181 & 70 & 85 & 86 & 24.6 & 2.4 \\
\hline Buttress plate & " & $"$ & 127 & 78 & 308 & 144 & 110 & 41 & 6.1 & 4.2 \\
\hline
\end{tabular}

+ This value estimated from fatigue relationship (Fig. 9 Ref. 7) for

* See Fig. 4. Values of $k_{d} / l_{d}$ were plotted against strain in Fig. 6 ,

RABLE 2

MEASURED STRAINS FOR DISSIPATORS

FOR DUNEDIN MOTORWAY OVERBRIDGES

\begin{tabular}{|c|c|c|c|c|c|c|c|}
\hline \multirow[t]{3}{*}{ Range of deflection } & \multicolumn{3}{|c|}{$93 \mathrm{~mm}$} & \multicolumn{3}{|c|}{$140 \mathrm{~mm}$} & \multirow{3}{*}{$\begin{array}{c}162 \mathrm{~mm} \\
\text { Range } \\
\text { of } \\
\text { strain } \\
\left(\frac{\circ}{8}\right)\end{array}$} \\
\hline & \multicolumn{2}{|c|}{$\begin{array}{l}\text { Strains }(\%) \text { from } \\
\text { initial mid-position }\end{array}$} & \multirow{2}{*}{$\begin{array}{l}\text { Range } \\
\text { of } \\
\text { strain } \\
\left(\frac{\circ}{0}\right)\end{array}$} & \multicolumn{2}{|c|}{$\begin{array}{c}\text { Strains ( }\left(\frac{8}{0}\right) \text { from } \\
\text { initial mid-position }\end{array}$} & \multirow{2}{*}{$\begin{array}{c}\text { Range } \\
\text { of } \\
\text { strain } \\
\left(\frac{0}{0}\right)\end{array}$} & \\
\hline & $\begin{array}{l}\text { Position } \\
\text { towards } \\
\text { jack }\end{array}$ & $\begin{array}{c}\text { Position } \\
\text { away from } \\
\text { jack }\end{array}$ & & $\begin{array}{l}\text { Position } \\
\text { towards } \\
\text { jack }\end{array}$ & $\begin{array}{l}\text { Position } \\
\text { away from } \\
\text { jack }\end{array}$ & & \\
\hline \multicolumn{8}{|l|}{ Demec points on jack side } \\
\hline Top 1 & -0.46 & +2.40 & 2.86 & -0.39 & +3.70 & 4.09 & 5.11 \\
\hline 2 & -0.99 & +2.21 & 3.20 & -1.36 & +3.56 & 4.92 & 5.70 \\
\hline 3 & -1.17 & +1.68 & 2.85 & -1.94 & +2.75 & 4.69 & 5.03 \\
\hline 4 & -1.28 & +1.39 & 2.67 & -2.30 & +2.14 & 4.44 & 5.12 \\
\hline Bottom 5 & -1.28 & +1.24 & 2.52 & -2.39 & +1.84 & 4.23 & 4.63 \\
\hline \multicolumn{8}{|l|}{$\frac{\text { Demec points on side away }}{\underline{\text { from jack }}}$} \\
\hline 1 & +.68 & -2.19 & 2.87 & +1.54 & - & - & 6.06 \\
\hline 2 & +1.04 & -1.80 & 2.84 & +1.65 & -3.34 & -4.99 & 5.89 \\
\hline 3 & +1.24 & -1.61 & 2.85 & +2.17 & -2.57 & -4.74 & 5.40 \\
\hline 4 & +1.30 & -1.33 & 2.63 & +2.40 & -2.22 & -4.62 & 4.98 \\
\hline 5 & +1.26 & -1.09 & 2.35 & +2.40 & -1.50 & -3.90 & 4.23 \\
\hline
\end{tabular}

At $150 \mathrm{~mm}$ strain range $\mathrm{k}_{d} / Q_{d}=72 \mathrm{~m}^{-1} \quad \mathrm{k}_{d} / Q_{d}=3.8 \mathrm{~m}^{-1} \quad Q_{d}=230 \mathrm{kN}$ approximately

and maximum strain $=6.06 \times \frac{150}{162}=5.6 \%$ 
TABLE 3

CYCLES OF LOADING APPLIED TO DISSIPATOR FOR DUNEDIN MOTORWAY OVERBRIDGE

\begin{tabular}{|c|c|c|c|c|c|c|c|c|}
\hline Date & $\begin{array}{l}\text { No. of } \\
\text { Cycles }\end{array}$ & $\begin{array}{c}\text { Travel } \\
(\mathrm{mm})\end{array}$ & Date & $\begin{array}{l}\text { No. of } \\
\text { Cycles }\end{array}$ & $\begin{array}{c}\text { Travel } \\
\text { (mm) }\end{array}$ & Date & $\begin{array}{l}\text { No. of } \\
\text { Cycles }\end{array}$ & $\begin{array}{c}\text { Travel } \\
\text { (mm) }\end{array}$ \\
\hline $14 / 9 / 78$ & $\begin{array}{l}2 \\
2 \\
2\end{array}$ & $\begin{array}{l}23 \\
55 \\
93\end{array}$ & $\begin{array}{c}14 / 9 / 78 \\
19 / 9 / 78 \\
19 / 9 / 78 \\
" \\
" \\
20 / 9 / 78 \\
" \\
21 / 9 / 78 \\
22 / 9 / 78 \\
22 / 9 / 78 \\
\text { Total }\end{array}$ & $\begin{array}{r}2 \\
2 \\
2 \\
2 \\
2 \\
2 \\
6 \\
2 \\
2 \\
8 \\
30 \\
\end{array}$ & $\begin{array}{l}142 \\
142 \\
145 \\
147 \\
154 \\
150 \\
150 \\
163 \\
163 \\
150\end{array}$ & $\begin{array}{r}25 / 9 / 78 \\
26 / 9 / 78 \\
\text { Total }\end{array}$ & $\begin{array}{c}22 \\
\frac{66}{88} \\
\text { Failure }\end{array}$ & $\begin{array}{l}100 \\
100\end{array}$ \\
\hline
\end{tabular}




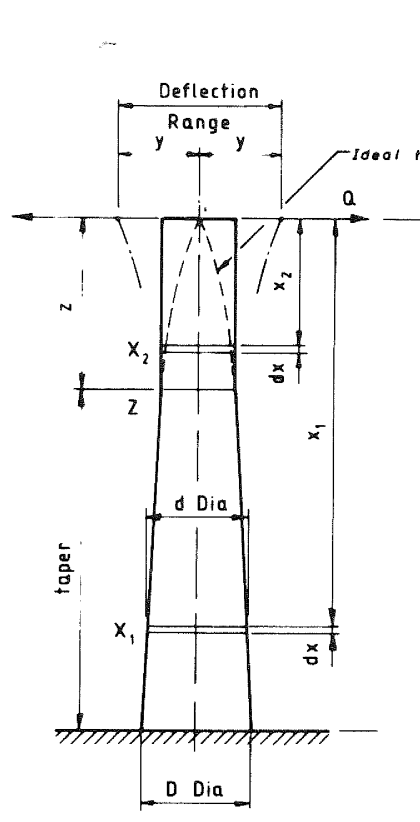

(a) Round Type

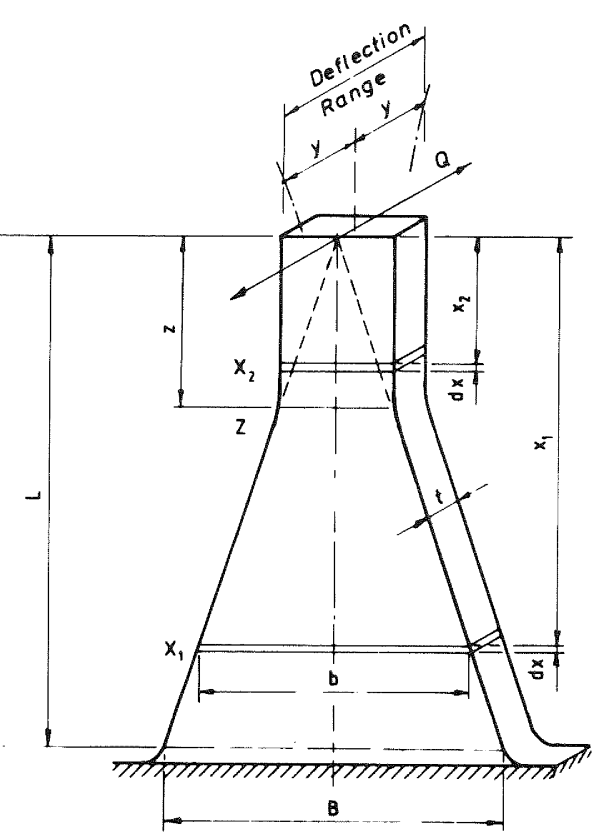

(b) Plate Type

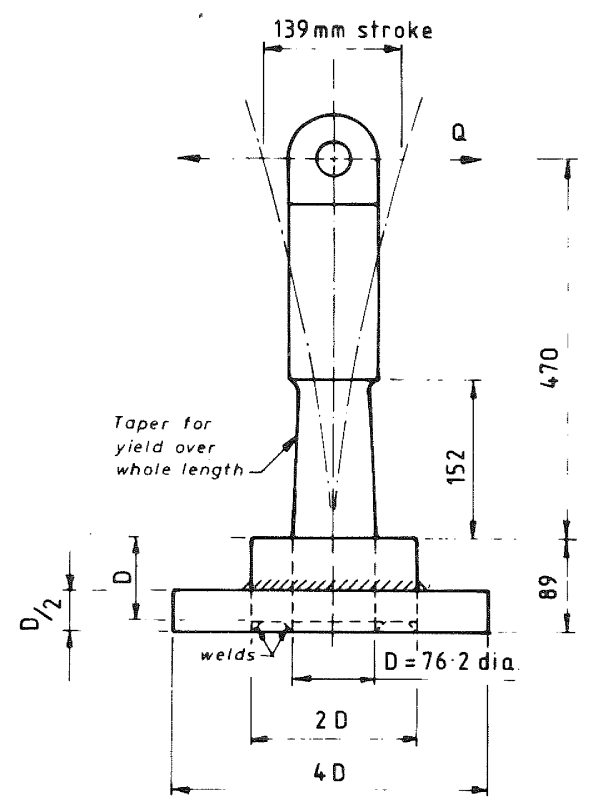

FIGURE 2: ROUND CANTILEVER DAMPER

FIGURE 1: TAPERED CANTILEVER DAMPERS

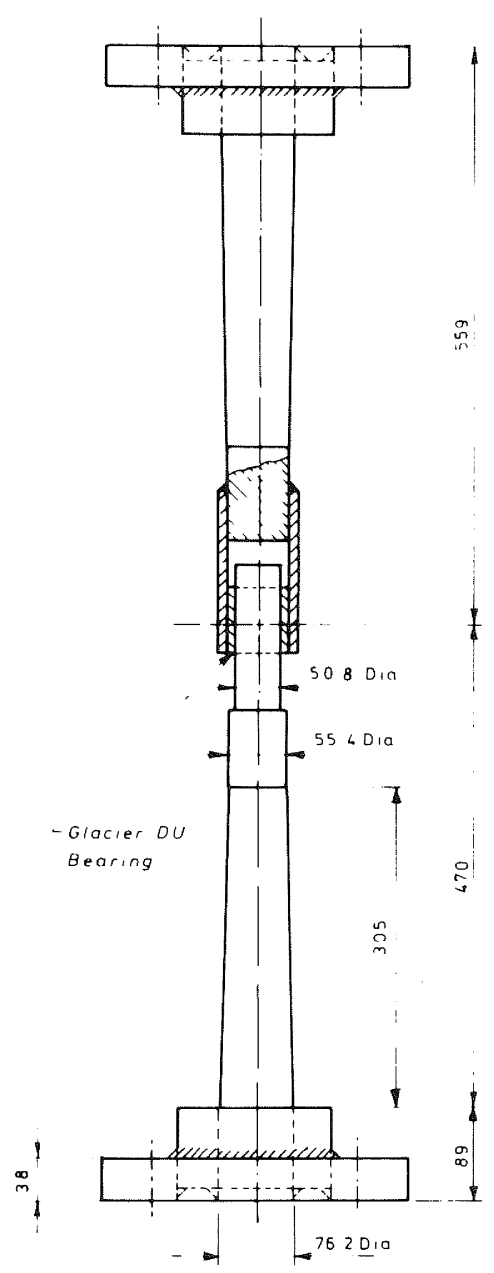

FIGURE 3: DOUBLE CANTILEVER DAMPER

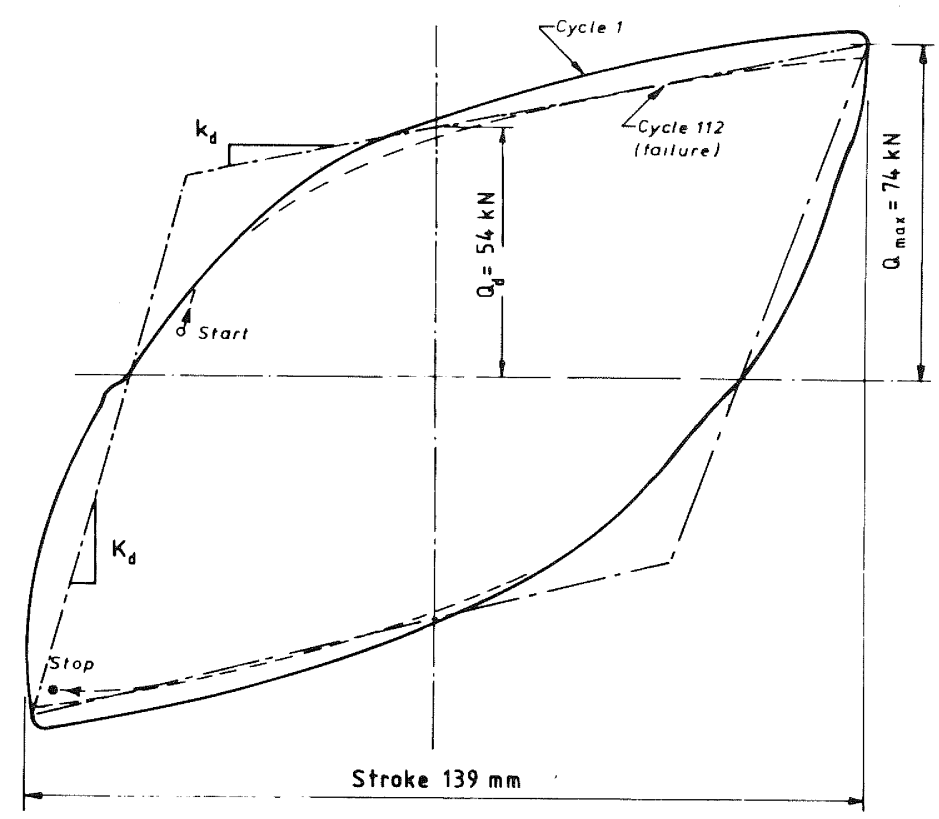

FIGURE 4: HYSTERESIS LOOP FOR

CANTILEVER DAMPER 


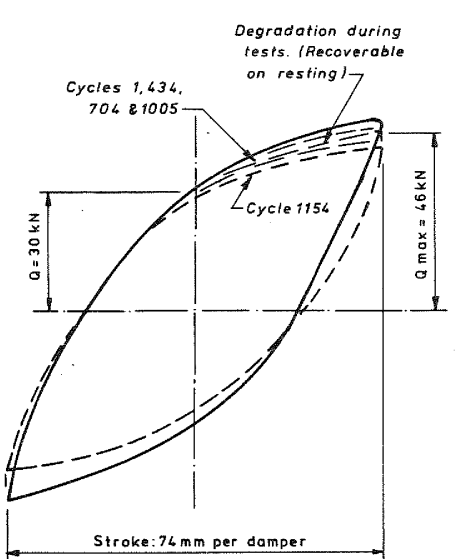

FIGURE 5: HYSTERESIS LOOP FOR DOUBLE CANTILEVER DAMPER

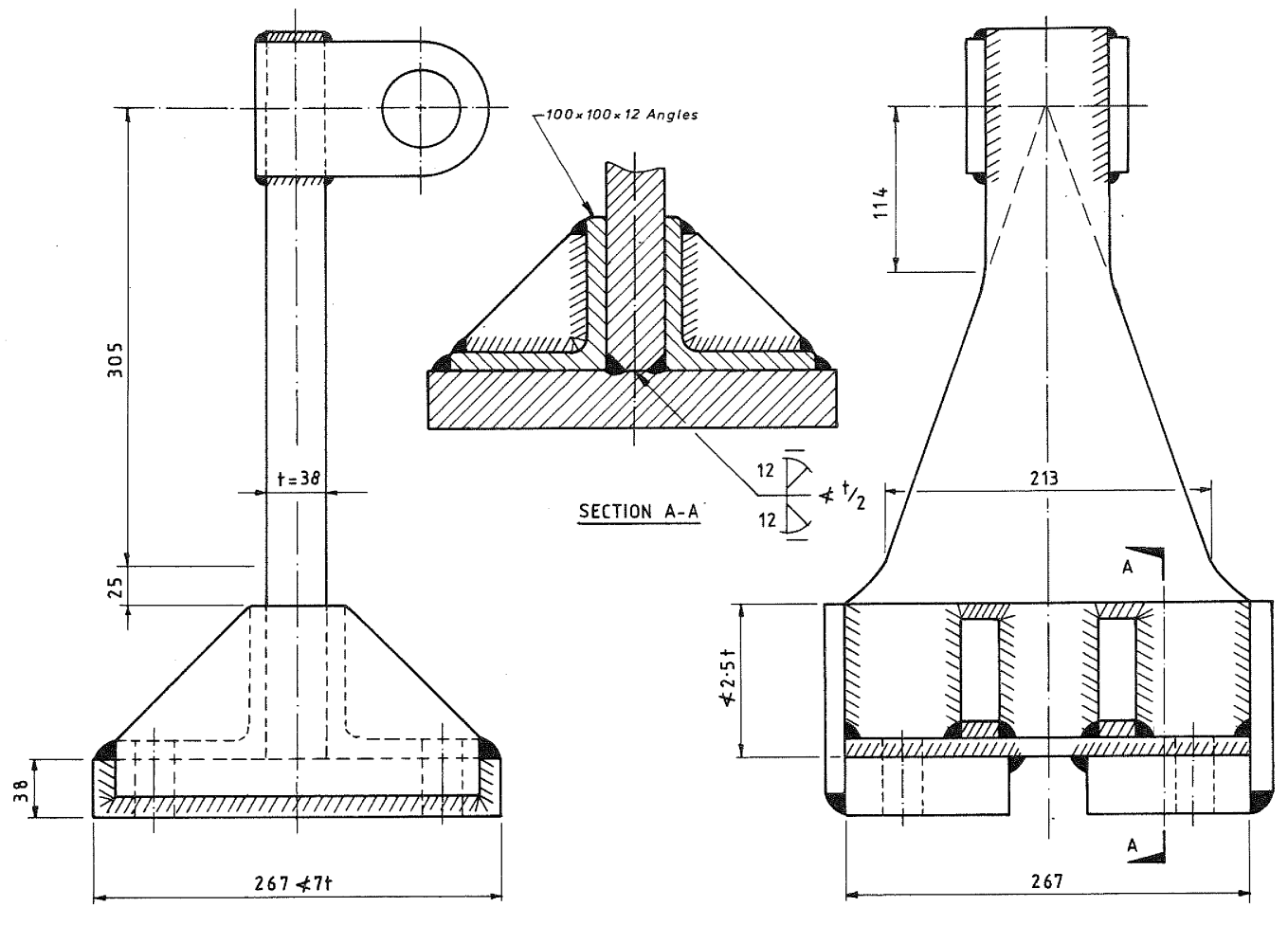

FIGURE 6: BUTTRESS DAMPER TESTED DURING DEVELOPMENT

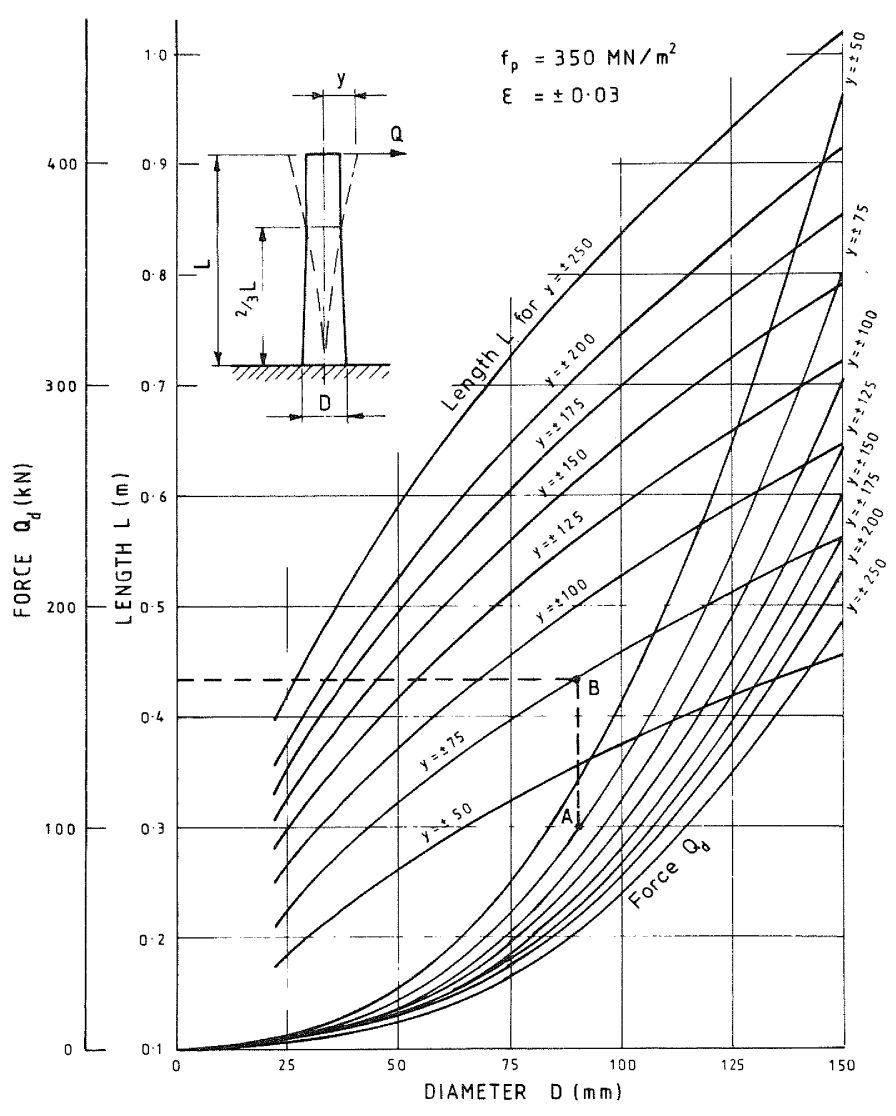

FIGURE 7: DESIGN CURVES FOR ROUND DAMPERS

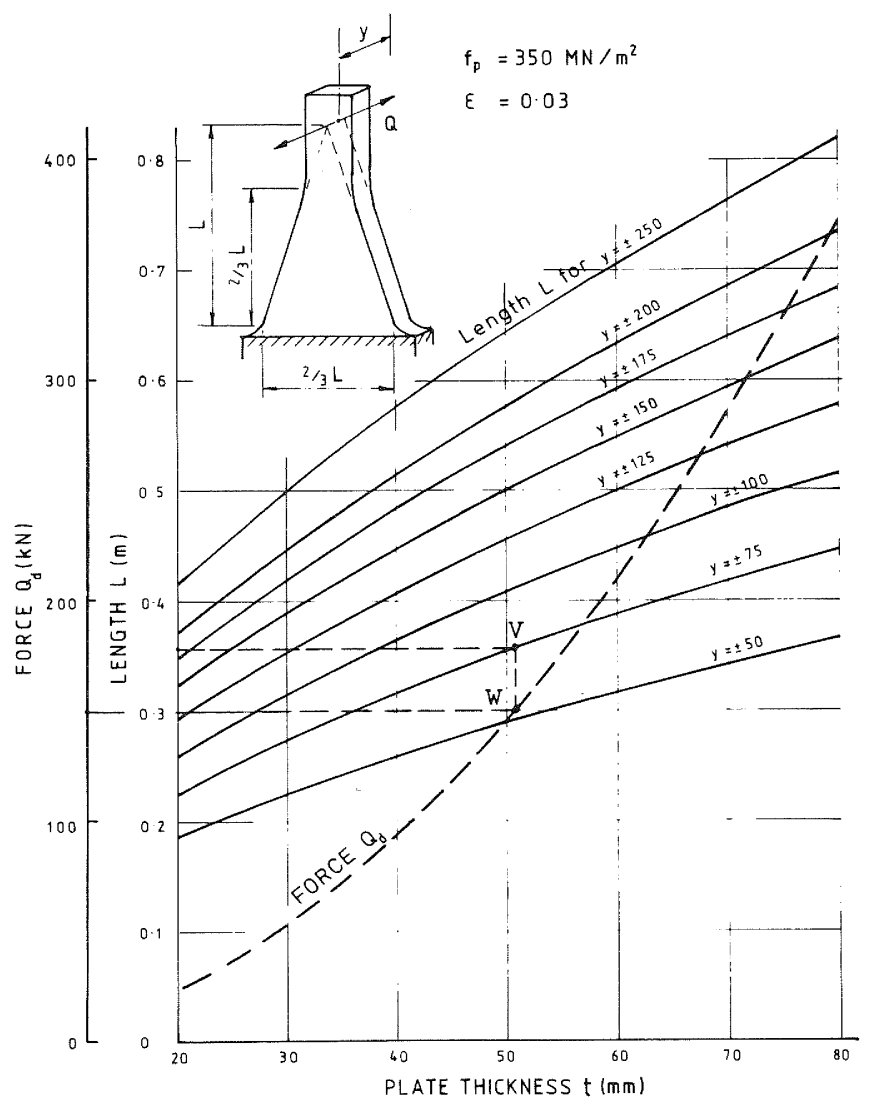

FIGURE 8: DESIGN CURVES FOR PLATE DAMPERS 

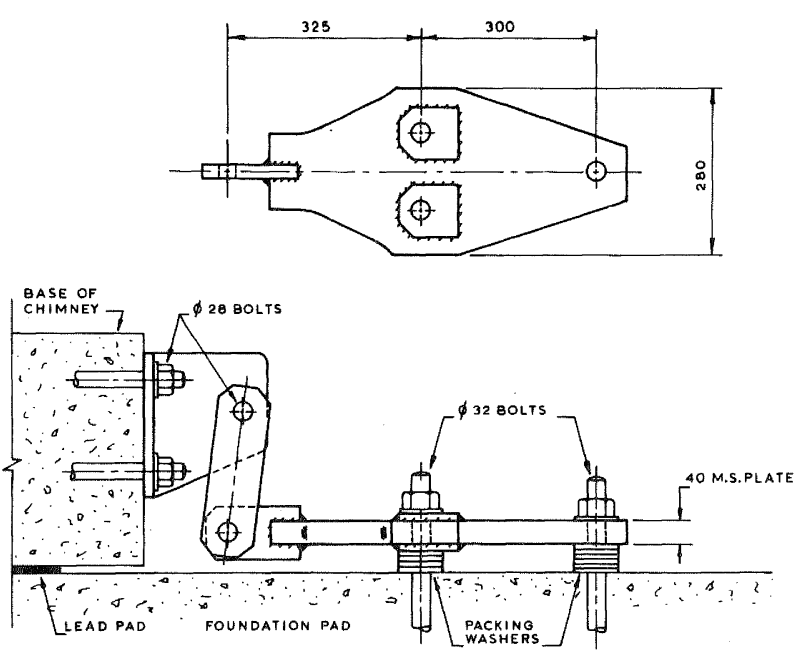

FIGURE 9: DAMPER FOR CHIMNEY FIGURE

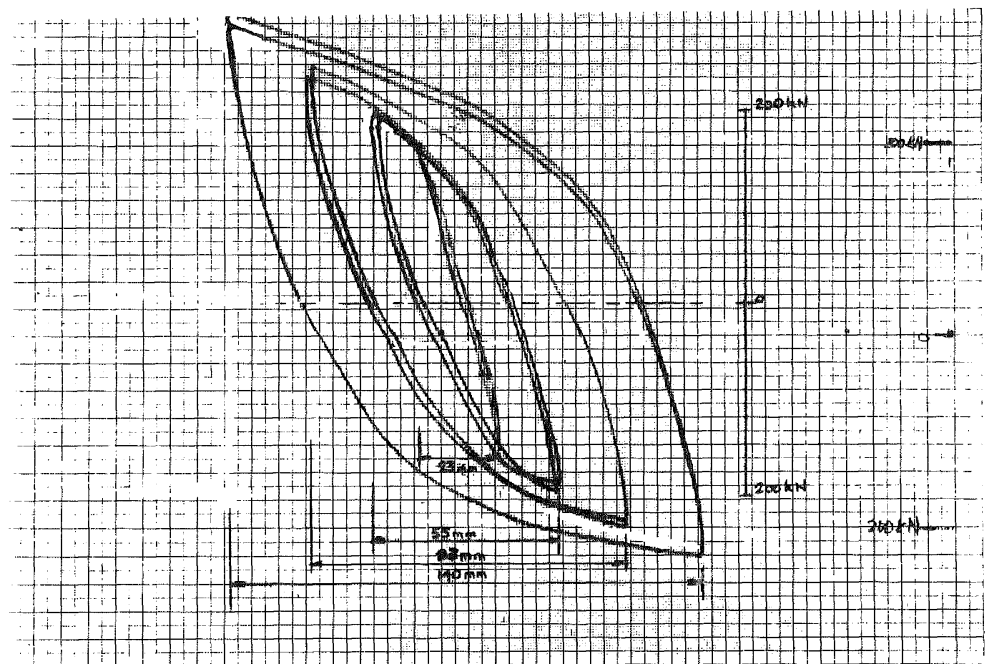

FIGURE 11a: FAMILY OF LOOPS FOR DAMPER FOR BRIDGE IN DUNEDIN
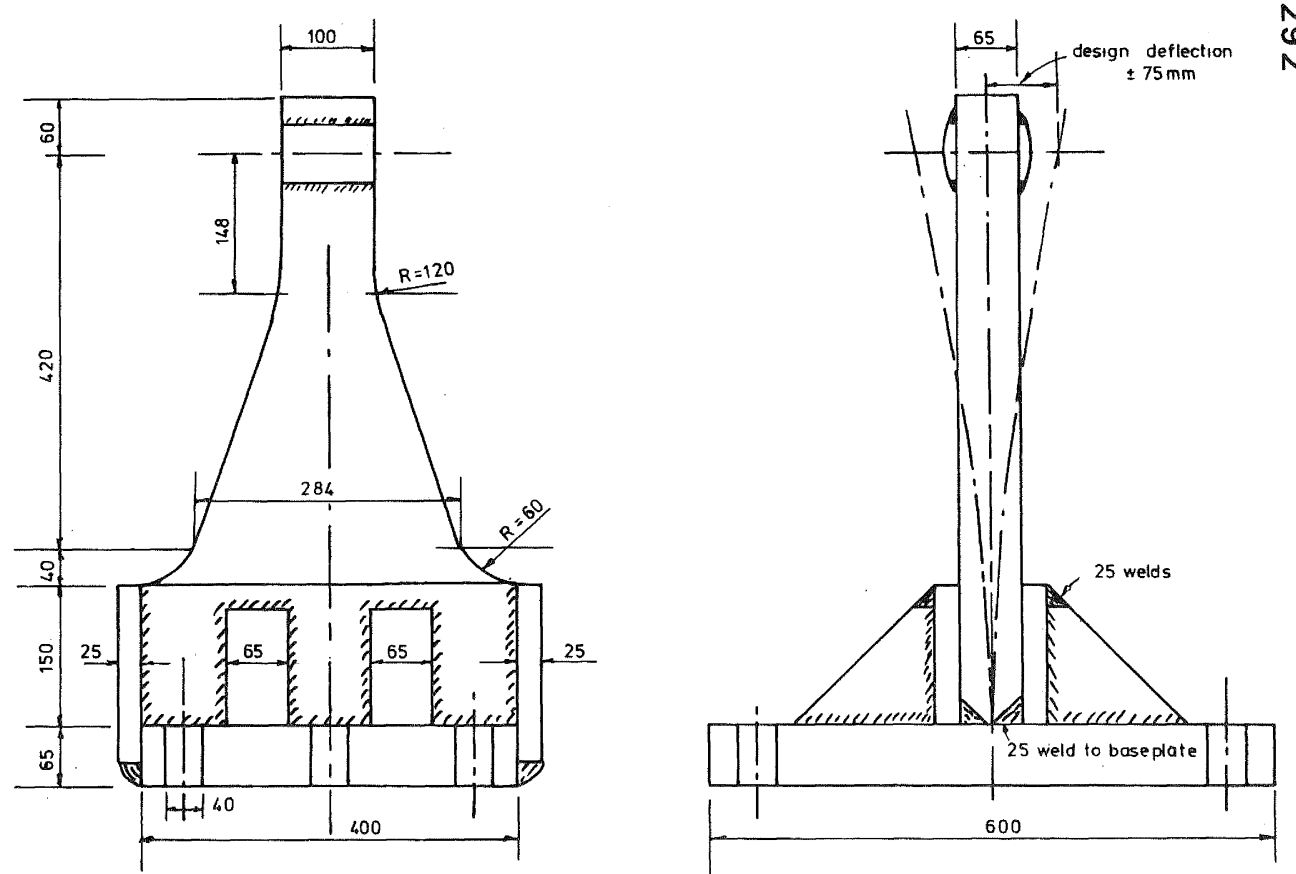

10: BUTTRESS DAMPER FOR BRIDGE IN DUNEDIN

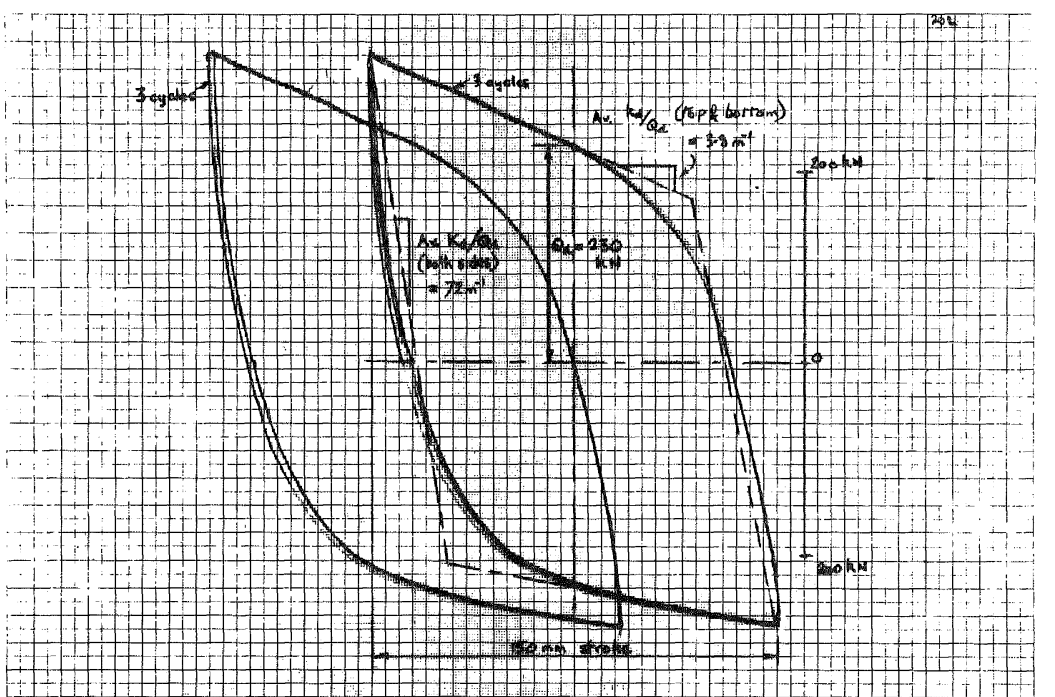

FIGURE 11b: LOOPS FOR $150 \mathrm{~mm}$ STROKE FOR DAMPER FOR BRIDGE IN DUNEDIN 


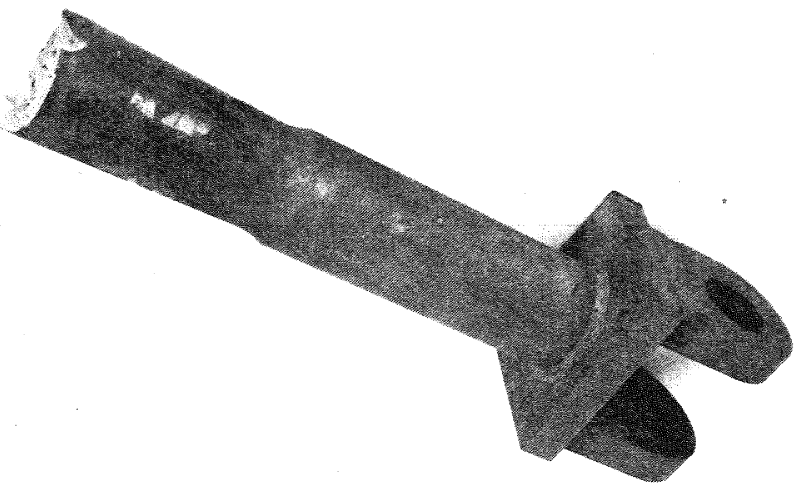

PLATE 1: FAILED ROUND DAMPER

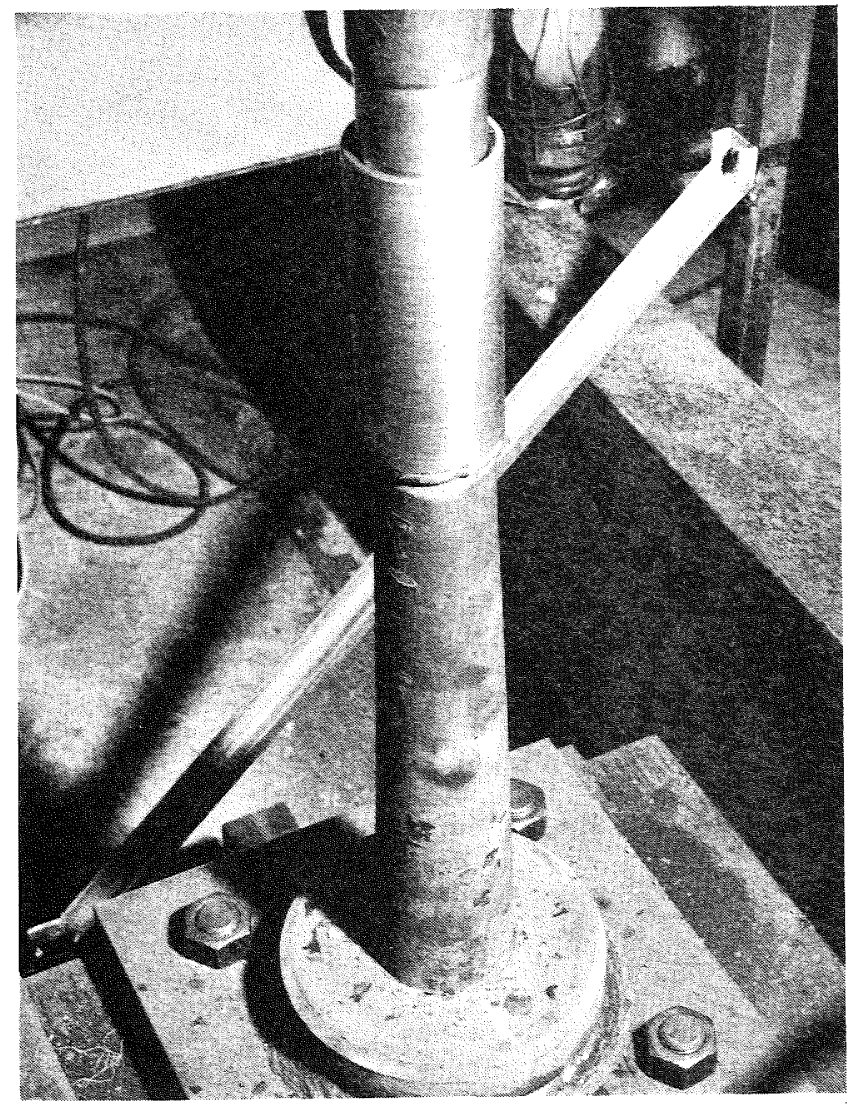

PLATE 3: DOUBLE CANTILEVER DAMPER IN TEST MACHINE AFTER TESTING

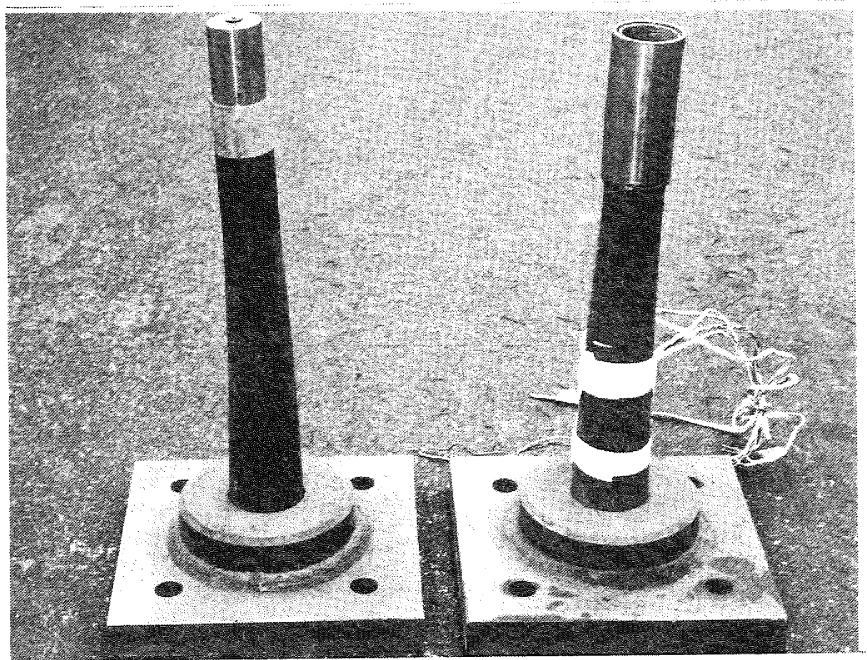

PLATE 2: DOUBLE CANTILEVER DAMPER IN TEST MACHINE AFTER TESTING

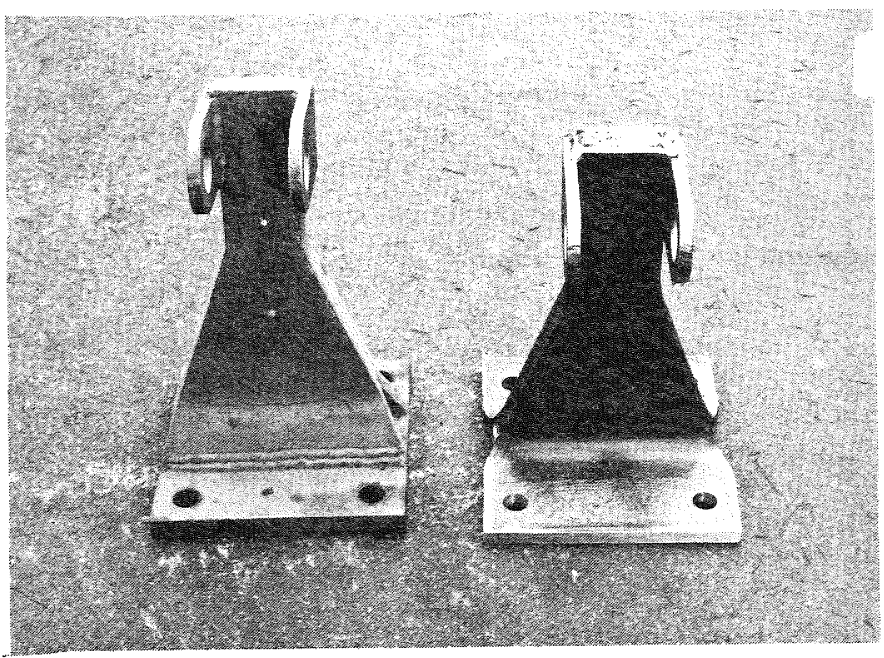

PLATE 4: SPLIT TYPE OF PLATE DAMPER LHS SEAM WELDED TYPE RHS 


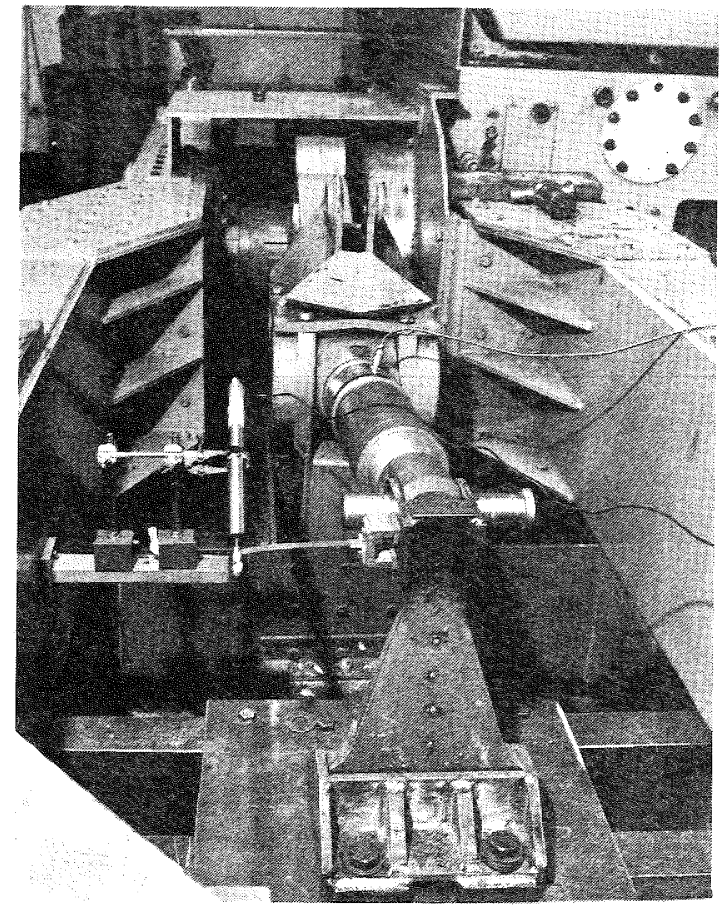

PLATE 5: BUTTRESS TYPE IN TEST MACHINE

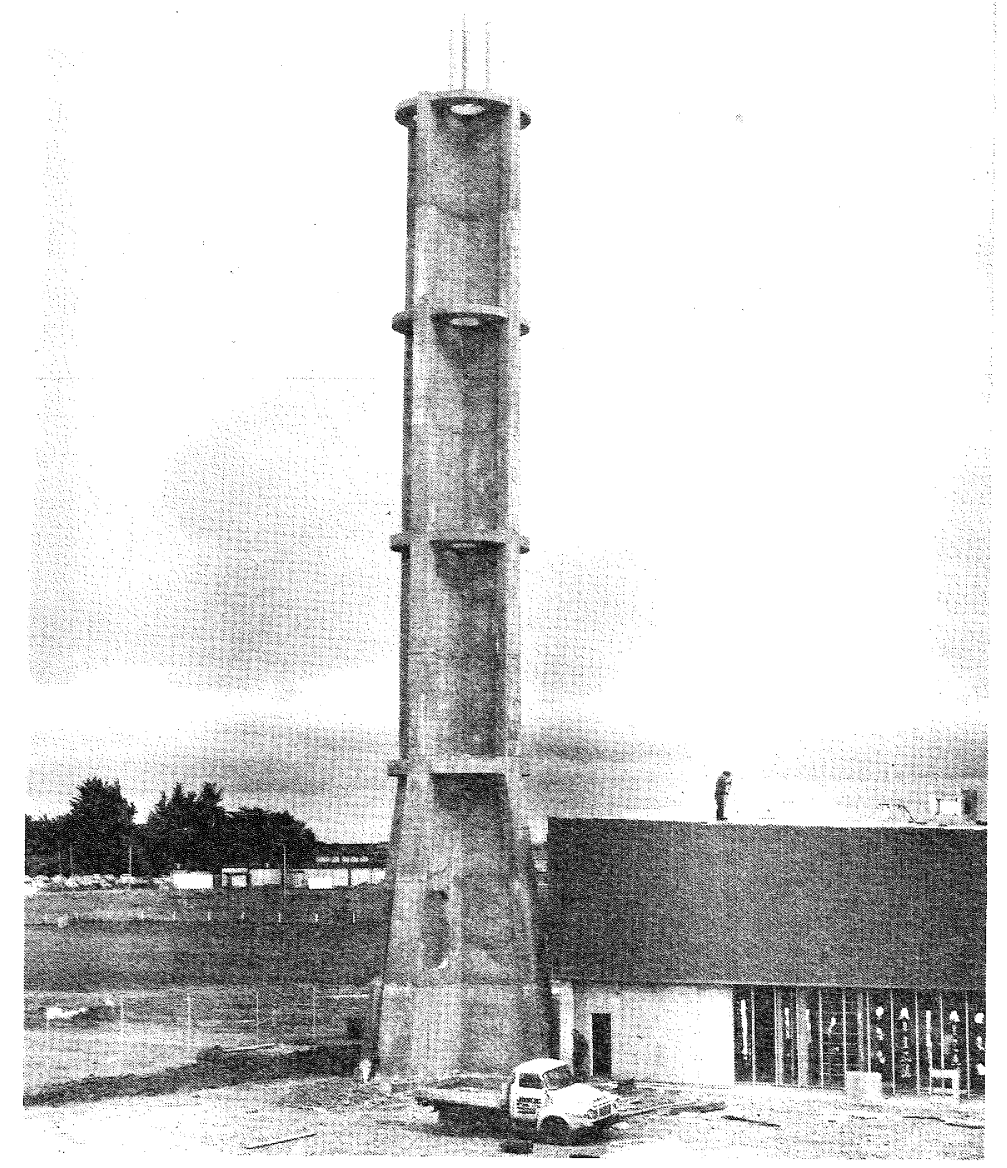

PLATE 6: CHIMNEY AT CHRISTCHURCH AIRPORT

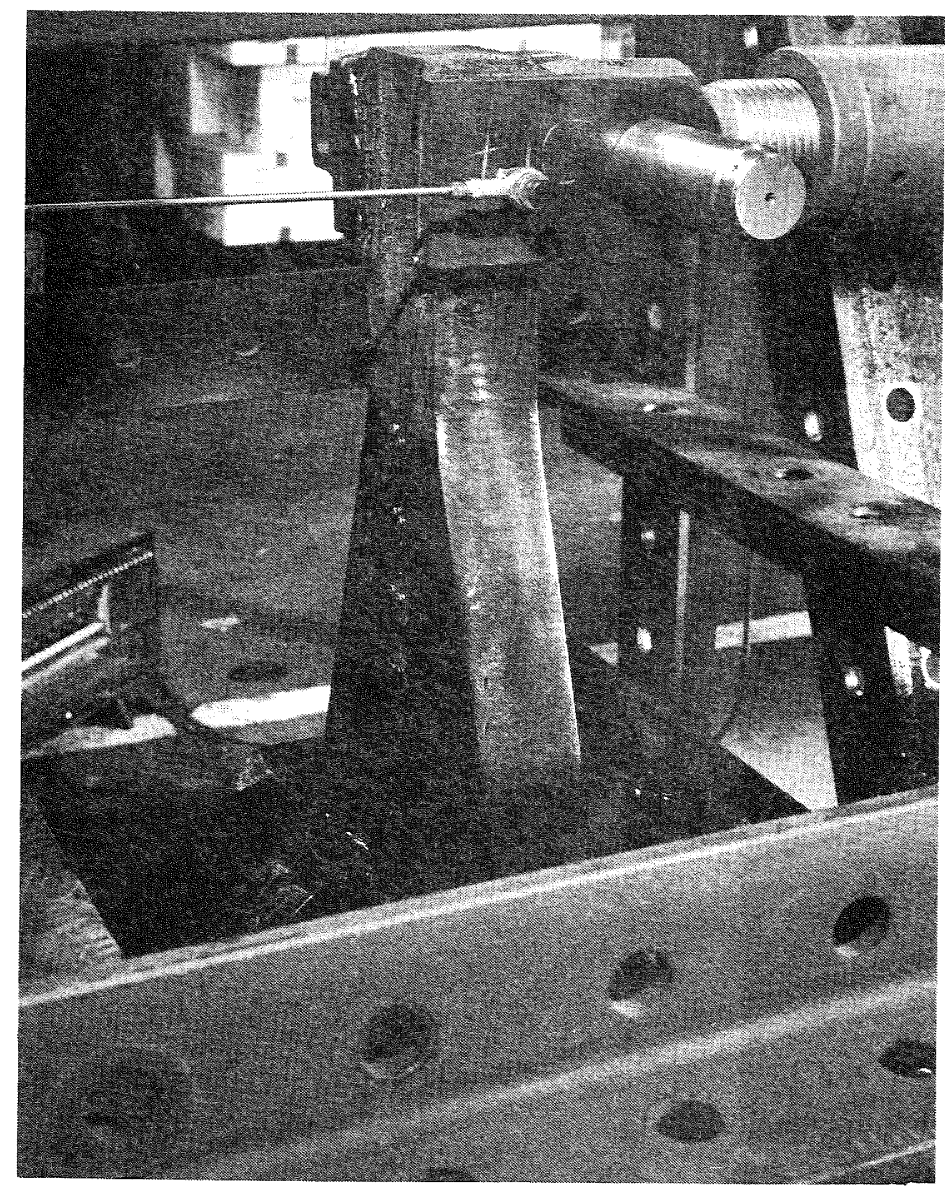

PLATE 7: DAMPER FOR DUNEDIN BRIDGE IN TEST FRAME PRIOR TO TESTING.

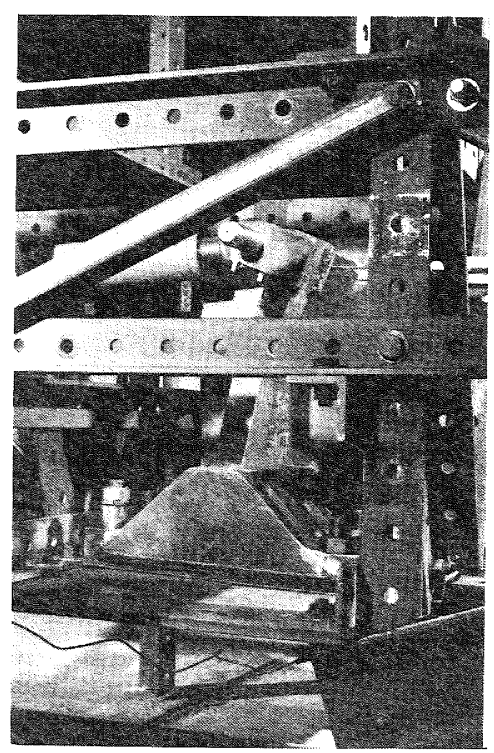

PLATE 8: DAMPER UNDER MAX̊!MUM DEFLECTION

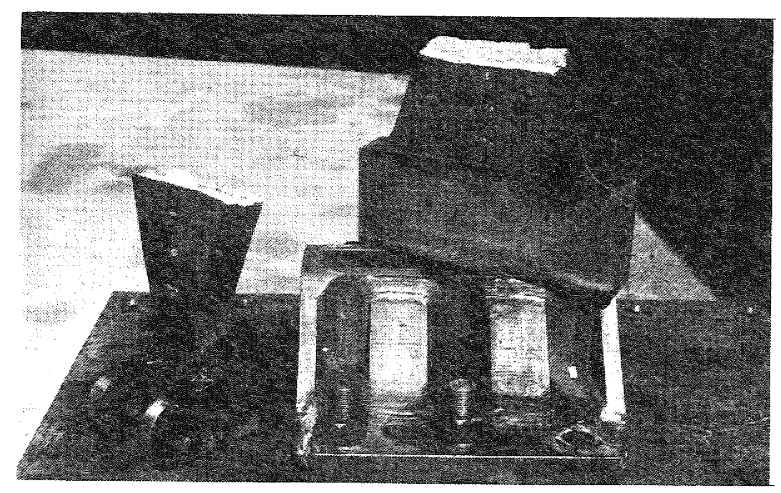

PLATE 9: DAMPER FAILED 